
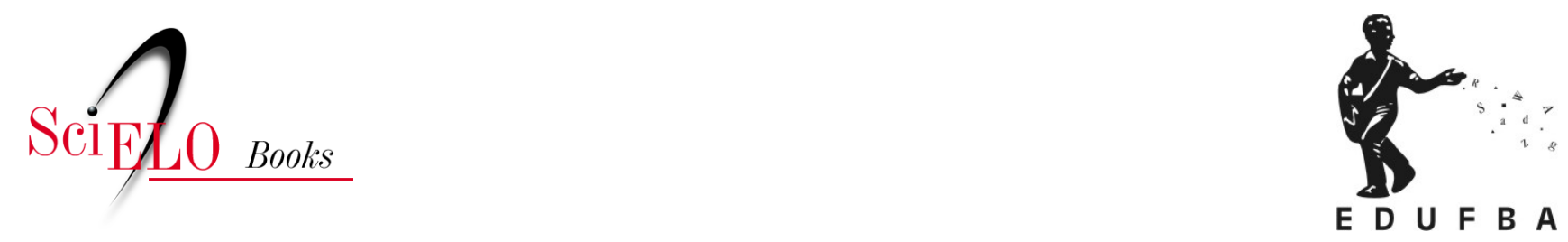

\title{
Policy \\ Avaliação da atenção à saúde bucal no Brasil: conceitos e abordagens
}

\author{
Sônia Chaves \\ Ana Carla Freitas Fonseca \\ Stella Maris Malpici Luna \\ Ana Maria Freire
}

CHAVES, S., FONSECA, A.C.F., LUNA, S.M.M., and FREIRE, A.M. Avaliação da atenção à saúde bucal no Brasil: conceitos e abordagens. In: CHAVES, S.C.L. Política de saúde bucal no Brasil: teoria e prática [online]. Salvador: EDUFBA, 2016, pp. 337-367. ISBN 978-85-232-2029-7.

https://doi.org/10.7476/9788523220297.0014.

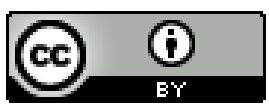

All the contents of this work, except where otherwise noted, is licensed under a Creative Commons Attribution 4.0 International license.

Todo o conteúdo deste trabalho, exceto quando houver ressalva, é publicado sob a licença Creative Commons Atribição 4.0. 


\title{
Avaliação da atenção à saúde bucal no Brasil
}

CONCEITOS E ABORDAGENS

\author{
Sônia Chaves \\ Ana Carla Freitas Fonseca \\ Stella Maris Malpici Luna \\ Ana Maria Freire
}

\section{A avaliação em saúde: situando o debate ao interior do ciclo da política pública}

Política pública é compreendida como conjunto de intervenções organizadas pelo Estado através de diferentes governos com a participação de agentes e instituições governamentais e não governamentais que visam enfrentar situações socialmente problemáticas e buscam a resolução ou melhor manejo delas. Por outro lado, a análise de políticas públicas é “[...] campo disciplinar do conhecimento que busca colocar o 'governo em ação' e/ou analisar essa ação e propor mudanças no rumo ou curso dessas ações”. (SOUZA, 2007, p. 69)

Na perspectiva do ciclo da política pública, a avaliação se refere ao momento de fim de um determinado decurso da política e também àquele em que se inicia ou não novo período da política em amadurecimento. As avaliações são sempre pretendidas e nem sempre realizadas, conforme os princípios da cientificidade exigidos. Certo é que ajustes são conduzidos pelos agentes envolvidos em sua implementação. Assim, a política pode ser reformulada, aprofundada, não implementada ou mesmo abandonada. 
O interesse do Estado na avaliação de políticas públicas depende dos agentes e do momento histórico haja vista a possibilidade de tais estudos legitimarem processos políticos ${ }^{1}$ em curso, bem como ser hoje aspecto fundamental da modernização da administração pública que está atenta à gestão por resultados ou na perspectiva do accountability. ${ }^{2}$ A realização de avaliações de políticas tem sido exigência comum dos organismos financiadores. Pode-se considerar que é prática e pesquisa em crescimento no Brasil, haja vista o aumento da produção acadêmica e a constituição dos grupos de pesquisa no Conselho Nacional de Desenvolvimento Científico e Tecnológico, ainda que em menor escala em relação a outros países. (FURTADO; VIEIRA-DA-SILVA, 2014)

Alerta se faz necessário ao debate na literatura da constatação de que o produto da pesquisa não é incorporado à gestão. A premissa de que as evidências científicas, produzidas por pesquisas avaliativas bem conduzidas acerca do sucesso ou fracasso de programas, seriam automaticamente utilizadas pelos tomadores de decisão, relacionando essas avaliações à implementação de ações para alcance dos resultados esperados, não é verdadeira. Somos mais cautelosos e há um entendimento de que variados e legítimos aspectos (interesses, valores, motivações, recursos) estão implicados nas decisões políticas e nos usos das avaliações para tomada de decisão. Logo, é importante lembrar que a avaliação é útil, mas é apenas mais uma entre várias dimensões que podem compor o conjunto de evidências para a tomada de decisão de gestores e stakeholders no rumo das políticas.

Por outro lado, é também a avaliação um dos componentes do Planejamento Estratégico Situacional (PES) (MATUS, 1994), onde ela é parte do momento tático-operacional, do fazer do plano, sendo a ferramenta que permite monitorar o avanço dos planos de ação em curso, permitindo sua manutenção em direção do "deve ser" ou a situação-objetivo traçada. Faz parte do quarto momento do PES, além dos momentos explicativo, normativo e estratégico. Tem, portanto, importância central na direcionalidade do plano, já que permite acompanhar

1 Refere-se a um conjunto de processos ao interior das organizações, geralmente conflituosos em torno do qual se define os rumos das respostas sociais do Estado que, muitas vezes, são frutos das relações de poder, sendo que é do interesse da ciência política explicar os prováveis déficits de implementação.

2 Refere-se à necessária prestação de contas de agentes do Estado em torno das políticas desenvolvidas em qualquer órgão da administração pública, mantida com recursos de toda a sociedade, tem como foco as instâncias controladoras ou a seus representados. 
seu desenrolar no processo político do jogo social. Os indicadores são instrumentos muito importantes nesse monitoramento.

\section{Os sentidos da avaliação em saúde: compartilhando conceitos}

A área de avaliação em saúde tem gradativamente se descolado das vertentes da política e do planejamento e gestão, tendo construído um saber e práticas próprias nos diferentes países. No caso brasileiro, a constituição desse subespaço no interior da saúde coletiva tem sido resultado da interação entre agentes dos campos burocrático e científico, respectivamente representados pelas instituições de gestão do Sistema Único de Saúde (SUS) e das universidades. (FURTADO; SILVA, 2014) Alerta é necessário ao pensar a avaliação em saúde no Brasil, já que esses autores apontam também que os agentes que atuam na área não se identificam como "avaliadores" ou, ao menos, como integrantes do espaço "da avaliação". A avaliação é mais uma atividade, um método utilizado, revelando a incipiência ou ambivalência desse espaço.

Importante destacar que a avaliação é um componente das práticas nos diversos âmbitos das políticas públicas em vários setores, o que gera uma grande polissemia conceitual e metodológica. (SILVA; FORMIGLI, 1994) A diversidade das definições sobre o que é avaliar e como fazê-lo é resultado dessa transversalidade da avaliação nos vários espaços ou microcosmos sociais, em que é ferramenta útil para a ação e também corresponde a pontos de vista diferentes, dependentes das posições ocupadas no espaço social. (SILVA, 2014)

Patton (1997) inclui na sua definição alguns aspectos como coleta de informações sobre as atividades, características e resultados dos programas para produzir julgamento sobre programas e subsidiar decisões sobre futuras programações. Weiss (1998) acrescenta uma concepção mais ampla, tratando-a como apreciação sistemática do funcionamento para além do acompanhamento dos objetivos traçados, mas analisando os processos para poder aprimorá-los.

Rossi e Freeman (1993, p. 5) definem a avaliação como “[...] a aplicação sistemática de procedimentos de pesquisa científica para verificar a conceitualização, design, implementação e utilidade dos programas de intervenção social". Esses autores consideram a avaliação como uma atividade complexa que envolve também decisões políticas e administrativas.

Autores como Guba e Lincoln (1989) ressaltam que a avaliação deve transcender a simples aplicação dos métodos de pesquisa científica, e incluir os diver- 
sos aspectos humanos, políticos, sociais, culturais e contextuais que envolvem todo o seu processo.

Entretanto, Champagne e colaboradores (2011, p. 44) apresentam uma definição que agrega mais elementos consensuais, adotada por este capítulo:

[...] avaliar consiste fundamentalmente em emitir um juízo de valor sobre uma intervenção, implementando um dispositivo capaz de fornecer informações cientificamente válidas e socialmente legítimas sobre essa intervenção ou sobre qualquer de um de seus componentes, com o objetivo de proceder de modo a que os diferentes atores envolvidos, cujos campos de julgamento são por vezes diferentes, estejam aptos a se posicionar sobre a intervenção para que possam construir individual ou coletivamente um julgamento que possa se traduzir em ações.

Adotamos esse conceito, onde avaliar, portanto, é antes de tudo fazer um julgamento de valor, julgamento do mérito de uma intervenção ou qualquer dos seus componentes com vistas ao auxílio na tomada de decisão por parte dos gestores, formuladores e implementadores de políticas (Figura 1). Esse julgamento de valor requer distintas abordagens. Ao refletir nas dificuldades enfrentadas de utilização dos resultados das avaliações, cada vez mais se reconhece que esse julgamento de valor sobre uma intervenção deve aportar conhecimento cientificamente válido e socialmente legítimo sobre ela, possibilitando que os diferentes agentes envolvidos, os quais geralmente ocupam posições distintas, estejam prontos a tomar posição sobre a intervenção e a construir individual e coletivamente um julgamento aproximado entre eles que possa se traduzir em ações de melhoria e transformação da intervenção. 
Figura 1 - A intervenção, seus principais componentes e principais características da intervenção (atributos) que podem ser avaliadas

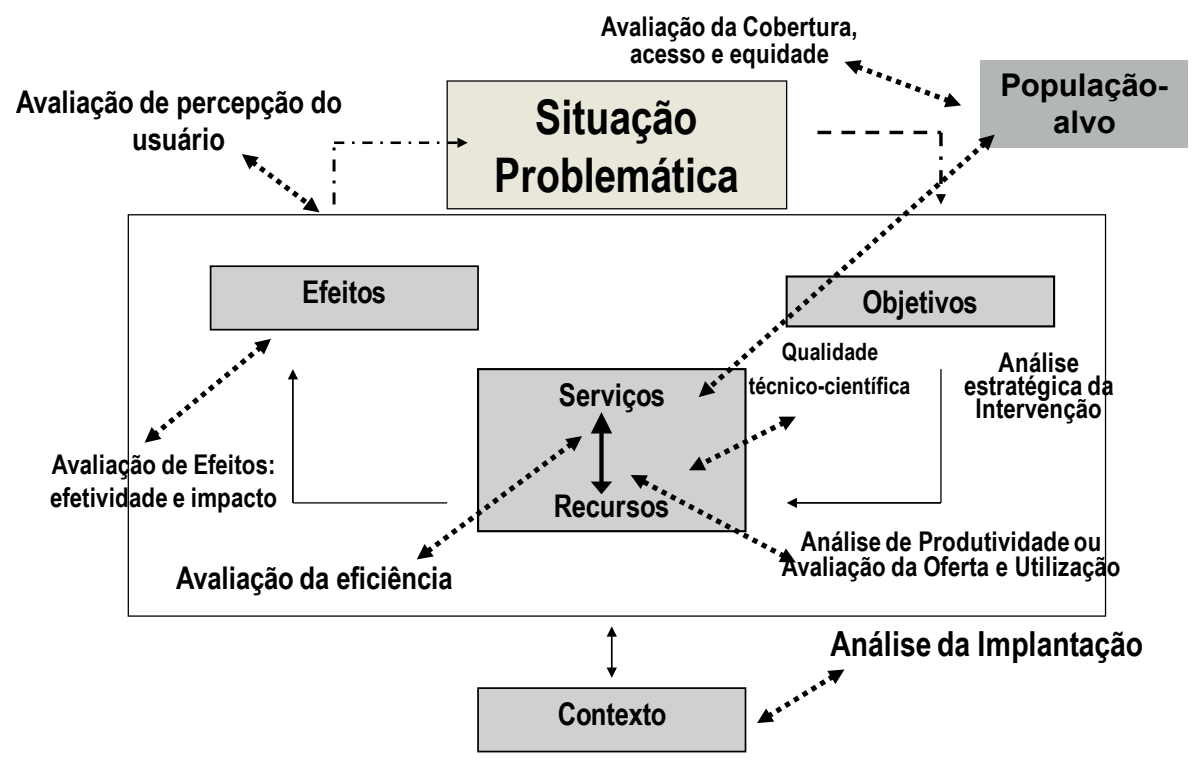

Fonte: adaptado de Contandriopoulos e colaboradores (1997).

Assim, é necessário perguntar: como devemos proceder para que todos os agentes envolvidos em uma intervenção possam conversar sobre ela, ter uma ideia em comum daquilo que ela é de maneira a poder fazer um julgamento sobre ela e agir?

É necessário também definir o que estamos denominando "intervenção", podendo ser sinônimo de programa. Intervenção é aqui compreendida como um sistema organizado de ação com seus componentes que, em um contexto e tempo determinado, podem modificar ou corrigir uma situação problemática, que são os agravos ou necessidades de saúde a serem enfrentados. Com isso, pode-se caracterizar diferentes tipos de intervenções. Desde programas e políticas, até intervenções técnicas como os protocolos clínicos (Figura 1). A intervenção compreendida como projetos, programas e planos pode ainda ser caracterizada como simples ou complexa ${ }^{3}$, e a abordagem e o método de avaliação dependerão do tipo e da complexidade dela.

Nas intervenção simples, os problemas podem ser resolvidos com solução única; nas complexas, procuram-se soluções que se apresentam de formas diversas, contraditórias ou opostas. (CHAMPAGNE et al., 2011) Será mais complexa quanto mais exigir ações de diferentes setores para resolver 
Segundo Cohen e Franco (1993, p. 85-86), os termos projeto, programa e plano designam modalidades de intervenção social que diferem em escopo e duração. Para esses autores:

[...] um plano é a soma dos programas que procuram objetivos comuns, ordena os objetivos gerais e os desagrega em objetivos específicos, que constituirão por sua vez os objetivos gerais dos programas. Ele determina o modelo de alocação de recursos resultante da decisão política e dispõe as ações programáticas em uma sequência temporal de acordo com a racionalidade técnica das mesmas e as prioridades de atendimento [...]. $\mathrm{O}$ plano inclui a estratégia, isto é, os meios estruturais e administrativos, assim como as formas de negociação, coordenação e direção.

Há conceitos diferentes para avaliação para a gestão ou avaliação normativa e pesquisa avaliativa. A avaliação normativa ou aquela para a gestão busca "apreciar cada um dos componentes da intervenção em função de critérios e normas. Ela se inscreve em um processo de verificação da conformidade dos componentes da intervenção em relação ao respeito às normas definidas". (BROUSSELLE et al., 2011, p. 44) Em outras palavras, avaliação normativa consiste em fazer um julgamento sobre uma intervenção, comparando os recursos empregados e sua organização (estrutura), os serviços ou bens produzidos (processo), e os efeitos obtidos (resultados), com critérios e normas, tendo como postulado que existe uma relação forte entre o respeito aos critérios e às normas escolhidas e os resultados do programa ou da intervenção. A tríade de Avedis Donabedian (estrutura, processo e resultado) é bastante utilizada em avaliações dessa natureza. A avaliação de uma intervenção voltada para a gestão é uma avaliação do tipo normativa, ou seja, relativa às normas estabelecidas. Esta deve ser estimulada como prática institucionalizada pelos serviços de saúde.

Por outro lado, a pesquisa avaliativa, como descrita por Contandriopoulos e colaboradores (1997), deve levar em consideração os fundamentos teóricos da intervenção, sua pertinência, sua produtividade e seus efeitos. Deve verificar o contexto que a gerou e buscar conhecer as relações entre contexto, processo e

a situação problemática. Um programa é uma intervenção, mas uma intervenção pode ser além do programa, uma política, uma ação organizada específica, por exemplo. 
resultados, de forma a ser capaz de produzir informações que permitam orientar efetivamente a tomada de decisões. Já Vieira-da-Silva (2014, p. 18) destaca:

A pesquisa avaliativa corresponde ao julgamento que se faz sobre as práticas sociais a partir de uma pergunta não respondida pela literatura especializada no tema a respeito das características dessas práticas em geral ou em um contexto particular mediante o recurso à metodologia científica. Já a pergunta que norteia a avaliação para a gestão decorre do desconhecimento sobre determinados aspectos da operacionalização de um programa ou intervenção específica. [...]

\section{Como conduzir uma avaliação}

O Quadro 1 sistematiza algumas possibilidades de avaliação a partir do estágio do programa. Tanto para avaliação de uma intervenção - do tipo avaliação normativa, por exemplo - quanto para uma pesquisa avaliativa, é desejável realizar uma importante etapa, geralmente exploratória, conhecida como estudo de avaliabilidade ou pré-avaliação, como um procedimento e método para determinar se a intervenção ou programa está minimamente implementado para ser objeto de uma avaliação sistemática. Essa, portanto, é uma característica importante de diferenciação de estudos avaliativos em relação a qualquer outro tipo. Somente podemos realizar uma avaliação se a intervenção já está em curso. É muito comum que haja o plano de ação como carta de intenções, mas não na prática, na concretude nas ações. Por isso, um estudo exploratório preliminar se a intervenção existe na prática é recomendado. 


\section{Quadro 1 - Os estágios de um programa, a proposta de avaliação e possíveis abordagens}

\begin{tabular}{|c|c|c|}
\hline $\begin{array}{l}\text { Estágio do } \\
\text { programa }\end{array}$ & Proposta de avaliação & Abordagem de avaliação \\
\hline $\begin{array}{l}\text { Planejamento do } \\
\text { Programa }\end{array}$ & $\begin{array}{c}\text { Produz informação pertinente } \\
\text { para ajudar os stakeholders no } \\
\text { desenvolvimento da racionalidade e } \\
\text { planejamento }\end{array}$ & $\begin{array}{c}\text { Avaliação formativa } \\
\text { Análise das necessidades }\end{array}$ \\
\hline $\begin{array}{l}\text { Implementação } \\
\text { inicial do } \\
\text { programa }\end{array}$ & $\begin{array}{c}\text { Produz informação a tempo sobre os } \\
\text { problemas de implementação para } \\
\text { auxiliar na sua estabilização }\end{array}$ & $\begin{array}{c}\text { Mapa conceitual (modelo } \\
\text { lógico) } \\
\text { Comentários ou advisory } \\
\text { Avaliabilidade } \\
\text { Avaliaçõesparticipativas }\end{array}$ \\
\hline $\begin{array}{l}\text { Estágio maduro } \\
\text { do programa }\end{array}$ & $\begin{array}{l}\text { Produz informação sobre os } \\
\text { problemas da implementação e as } \\
\text { fontes para melhor o seu processo } \\
\text { Monitorando o progresso da } \\
\text { implementação } \\
\text { Avaliação do processo de } \\
\text { implementação }\end{array}$ & $\begin{array}{c}\text { Avaliação formativa } \\
\text { Revisão do programa/reuniões } \\
\text { de desenvolvimento } \\
\text { Avaliação do processo guiada } \\
\text { pela teoria (teory-driven } \\
\text { process evaluation) }\end{array}$ \\
\hline $\begin{array}{l}\text { Resultados do } \\
\text { programa }\end{array}$ & $\begin{array}{l}\text { Avalia se um programa está pronto } \\
\text { para avaliação de resultados } \\
\text { Monitora o desempenho do programa } \\
\text { Avalia o desempenho do programa } \\
\text { segundo seus efeitos }\end{array}$ & $\begin{array}{c}\text { Evaluability assessment } \\
\text { Monitoramento do } \\
\text { desempenho } \\
\text { avaliação dos efeitos do } \\
\text { programa (efetividade e } \\
\text { impacto) } \\
\text { Avaliação dos resultados guiada } \\
\text { pela teoria (teory-driven } \\
\text { process evaluation) }\end{array}$ \\
\hline
\end{tabular}

Fonte: adaptado de Chen (2005).

Para merecer uma avaliação extensa, o programa deve satisfazer três critérios: 1) operar como previsto; 2) ser relativamente estável ao longo do tempo; e 3) indicar estar alcançando algum resultado positivo. Contudo, frequentemente, os objetivos do programa não estão bem definidos, ou não ficaram claros para os profissionais que atuam nos diversos níveis; a implantação não foi feita 
conforme previsto no plano e não há ainda tempo técnico suficiente para que os resultados esperados possam ter sido produzidos. Além disso, também é comum que os diversos gestores e profissionais responsáveis pela implementação do programa tenham concepções distintas acerca dos objetivos do programa, assim como sobre os aspectos mais frágeis que requerem avaliação bem como sobre os possíveis usos dos resultados obtidos. A análise exploratória dessas questões vem sendo denominada de "avaliabilidade" - Evaluability Assessment (EA). Trata-se de uma pré-avaliação realizada para identificar se um programa é bem concebido e consistentemente implementado de forma a poder se submeter a uma avaliação sistemática. (PATTON, 2002) Particularmente, antes de se realizar uma avaliação sobre a efetividade de um programa, é recomendada a realização de um estudo de avaliabilidade para evitar gastos desnecessários em termos de tempo e recursos humanos e materiais que envolvem uma avaliação desse porte. (CHEN, 2005)

Assim, a EA é o exame sistemático e preliminar de um programa, em sua teoria e em sua prática, para determinar se há justificativa para uma avaliação extensa e (ou) para melhor delimitar os objetivos do programa bem como identificar áreas críticas a serem priorizadas na avaliação. A EA pode ser considerada como um processo voltado para clarificar os desenhos dos programas, explorando sua realidade e, se necessário, ajudando a redesenhá-lo. Essa estratégia não somente nos mostra se o programa pode ser avaliado, mas também se a avaliação é capaz de contribuir para melhorar o seu desempenho. Dessa forma, seus objetivos podem ser os seguintes:

- Identificar se os objetivos do programa estão claramente formulados;

- Identificar se há concordância entre os diversos profissionais acerca dos objetivos, metas e população-alvo do programa;

- Discutir as relações entre problemas, objetivos e atividades verificando a plausibilidade das atividades como pertinentes para atingir os objetivos tendo em vista os seus determinantes e os objetivos e recursos (análise estratégica);

- Identificar se os formuladores de políticas ou gestores estão aptos ou dispostos para usar as informações da avaliação para mudar o programa.

A EA envolve diversas etapas: 1) clarificação dos objetivos da intervenção. Pode ser feita através de revisão da documentação do programa e entrevistas 
junto a gestores e profissionais envolvidos na sua execução (aqueles com interesse no programa ou em sua avaliação); 2) elaboração do modelo lógico 4 do programa, que é a modelização da intervenção com atenção especial para relações entre o problema, seus determinantes, o que o programa faz (a intervenção) e o que se espera que alcance (os resultados). Nessa vertente, faz-se uma análise da plausibilidade dessas relações, ou seja, uma análise lógica da teoria do programa. (MEDINA et al., 2005) A principal técnica nessa fase é a análise documental. Após a elaboração preliminar do modelo lógico a partir da consulta aos documentos, este deve ser apresentado aos gestores na busca de uma verificação se o "modelo no papel" corresponde àquele que está na representação dos profissionais; (3) descrição do funcionamento do programa na prática. Nessa etapa, pretende-se estimar de maneira aproximada qual o estágio de implantação do programa, como ele está funcionando na prática (o modelo da intervenção prático), o que se sabe e o que não se sabe sobre ele. (PATTON, 2002) Os dados para responder a essas questões devem ser obtidos através de entrevistas com informantes-chave e observação in loco. Essa etapa inclui comparação da realidade do programa com o modelo feito previamente, seguido pela apresentação subsequente aos gestores para novo feedback; 4) elaboração de recomendações. O objetivo final das etapas anteriores é reunir informações capazes de: identificar áreas para melhoria do programa, identificar componentes do programa sobre os quais não se tem informação (perguntas para avaliação) e identificar quais questões de avaliação são plausíveis e úteis para o mesmo. É imperativo a publicização dos resultados na medida em que, ao explicitar os resultados preliminares e finais do modelo lógico proposto, e as lacunas nos objetivos e atividades, por exemplo, essa estratégia se aproxime das correntes participativas da avaliaçao. A EA pode se constituir em uma avaliação para a gestão já que permite a reflexão sobre seu desenvolvimento em momentos de reunião conjunta entre gestores, executores, beneficiários e avaliadores.

$4 \quad$ O modelo lógico de um programa é definido como uma imagem da teoria e os pressupostos subjacentes ao programa. Um modelo lógico de um programa conecta resultados (tanto de curto quanto de longo prazo) às atividades/processos do programa e aos seus pressupostos teóricos, sendo uma maneira sistemática e visual de apresentar e compartilhar as relações entre os recursos para operar o programa, as atividades planejadas e as mudanças ou resultados a serem alcançados. 
As informações podem ser obtidas de diversas fontes tais como: análise de documentos (planos e relatórios), entrevistas com informantes-chave e observação in loco da intervenção.

Análise de documentos: os principais documentos relacionados com o programa devem ser analisados visando principalmente esclarecer os objetivos e metas, a situação atual do problema e seus determinantes e a relação entre os primeiros e os últimos. Ou seja, em que medida os objetivos e metas são adequados à atual situação do problema e suas causas?

Entrevistas com informantes-chave: informantes-chave são pessoas que conhecem em profundidade a situação, ou seus aspectos, que se quer investigar. Sua escolha é de fundamental importância para obter as informações desejadas. São as pessoas que coordenam e executam o programa nos seus diversos níveis. Os usuários são também informantes relevantes tendo em vista que grande parte do funcionamento real do programa pode ser apreendido através da sua satisfação. As entrevistas podem ser gravadas ou anotadas.

Observação: a observação é uma técnica das mais importantes, nessa etapa, pois frequentemente há uma distância entre o que está nos planos daquilo que os profissionais pensam do que está de fato acontecendo na prática. Ela deve focalizar o funcionamento do programa e indagar se as atividades previstas estão sendo realizadas e de que forma. Deve ser feita de forma sistemática a partir de um roteiro e ser registrada em um diário de campo.

Um exemplo de formulação de um modelo lógico de uma intervenção na saúde bucal é o modelo que expressa o esperado da implementação dos serviços odontológicos especializados (Figura 2).

Pode-se observar que esse modelo lógico proposto descreve sucintamente o ciclo da política desde a formulação, onde foram definidos seus objetivos principais pelo Ministério da Saúde, que seriam a oferta e acesso à atenção secundária e a busca da integralidade nas ações de saúde bucal. Para isso, o Governo Federal instituiu critérios, normas e requisitos para implantação e credenciamento dos Centros de Especialidades Odontológicas (CEO), bem como formas de financiamento, além de propor Protocolos Assistenciais específicos para a atenção especializada, que pudessem facilitar a etapa da implementação. No sentido da integralidade, o estabelecimento dos fluxos de referência e contrarreferência para diversas especialidades dos CEO são incentivados. Por outro lado, no nível local, esses objetivos seriam expressos nas práticas de gestão e assistenciais que incluem: a) oferta de serviços especializados de endodontia, 
Figura 2 - Modelo lógico da Atenção Especializada em saúde Bucal na Política Nacional de Saúde Bucal no nível local segundo seus objetivos, atividades e resultados esperados no ciclo da política, 2004-2014

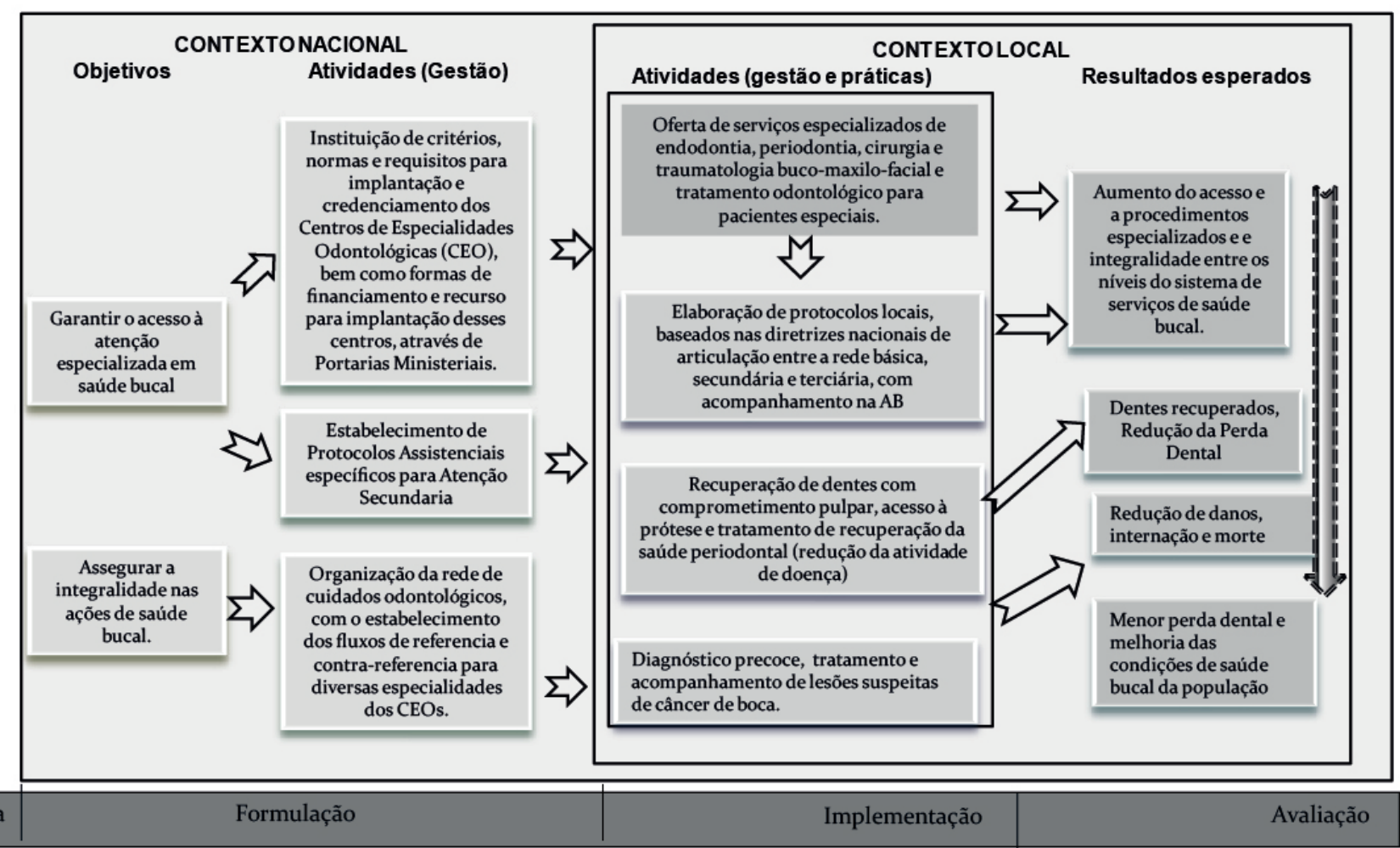

Fonte: Elaboração dos autores. 
periodontia, cirurgia e traumatologia buco-maxilo-facial e tratamento odontológico para pacientes especiais; b) elaboração de protocolos locais, baseados nas diretrizes nacionais de articulação entre a rede básica, secundária e terciária, com acompanhamento pela atenção básica; c) recuperação de dentes com comprometimento pulpar e recuperação da saúde periodontal (redução da atividade de doença); além do d) diagnóstico precoce, tratamento e acompanhamento de lesões suspeitas de câncer de boca. Os possíveis resultados esperados, ainda que não expressos explicitamente nos documentos oficiais, são: aumento do acesso da população aos procedimentos especializados, redução da perda dental e outros danos relacionados, maior integralidade entre os níveis do sistema de serviços de saúde bucal e, portanto, melhoria das condições de saúde bucal da população. Esses resultados esperados são objeto de análise no momento da avaliação do ciclo da política, podendo indicar novos rumos como o abandono, aprofundamento ou mudança. Desse modo, a partir desse modelo, foram derivadas as principais dimensões e critérios para avaliação preliminar (avaliabilidade), onde foram consideradas as seguintes categorias: a) os objetivos do CEO segundo os stakeholders; b) os principais resultados identificados pelos gestores e executores; c) a organização do serviço; d) a articulação com a atenção básica; e e) os principais aspectos para a melhoria do programa (Quadro 2).

Para Wholey (2004), o EA é uma importante ferramenta de gestão. O autor propõe como método para conduzir um EA a realização de entrevistas com gestores e formuladores de políticas, visitas ao local para observar o programa em operação e a análise dos seus documentos. 


\section{Quadro 2 - Principais dimensões e critérios para análise da implementação da atenção secundária na Política Nacional de Saúde Bucal (PNSB), 2009}

\begin{tabular}{|c|c|c|}
\hline Dimensão & Critério & Fonte de evidência \\
\hline Objetivos & $\begin{array}{l}\text { Os objetivos do } \\
\text { serviço }\end{array}$ & $\begin{array}{c}\text { Análise documental e entrevistas } \\
\text { Em sua opinião, quais são os principais objetivos } \\
\text { do CEO? } \\
\text { Da apresentação do Programa, o que você se } \\
\text { lembra do proposto nos documentos? }\end{array}$ \\
\hline \multirow[t]{2}{*}{$\begin{array}{c}\text { Atividades (gestão } \\
\text { e práticas) }\end{array}$} & $\begin{array}{l}\text { A organização do } \\
\text { serviço }\end{array}$ & $\begin{array}{c}\text { Entrevista: } \\
\text { Descreva as atividades que você desenvolve. Cite } \\
\text { exemplos. } \\
\text { Qual o número de atendimentos diários feitos } \\
\text { por você neste serviço? } \\
\text { Há um padrão proposto pelo serviço de } \\
\text { produção diária ou mensal? } \\
\text { Observação in loco: tempo de consulta, horário } \\
\text { de início e fim das atividades do turno de } \\
\text { trabalho. }\end{array}$ \\
\hline & $\begin{array}{l}\text { A articulação com } \\
\text { a atenção básica } \\
\text { e os protocolos } \\
\text { assistenciais }\end{array}$ & $\begin{array}{c}\text { Entrevista: } \\
\text { Como se organiza o acesso ao CEO no município } \\
\text { (a articulação com a rede básica)? }\end{array}$ \\
\hline Resultados & $\begin{array}{l}\text { Os principais } \\
\text { resultados } \\
\text { identificados }\end{array}$ & $\begin{array}{l}\text { Entrevista: } \\
\text { Na sua opinião, quais os principais resultados } \\
\text { observados por você aqui no serviço de saúde? }\end{array}$ \\
\hline Lacunas & $\begin{array}{l}\text { Os principais } \\
\text { aspectos para } \\
\text { melhoria }\end{array}$ & $\begin{array}{c}\text { Entrevista: } \\
\text { Quais seriam suas principais recomendações para } \\
\text { a melhoria do CEO } \\
\text { Quais são suas principais dificuldades que você } \\
\text { enfrenta na coordenação deste serviço? }\end{array}$ \\
\hline
\end{tabular}

Fonte: Rossi e Chaves (2015). 


\section{Outros atributos a serem avaliados}

Em seguida, ao constatar que a intervenção está operando como previsto e pode ser avaliada, pode-se conduzir uma pesquisa avaliativa a partir do estudo de mais características dessa intervenção como a análise estratégica ${ }^{5}$, a lógica, a produtividade, os efeitos, a eficiência, e a análise da implantação (BROUSSELLE et al., 2011), ainda que Vieira-da-Silva (2014) considere outros atributos como a acessibilidade, cobertura, qualidade técnico-científica, entre outros (Figura 1). Neste capítulo, focaremos mais especificamente na avaliação da cobertura e utilização como ferramentas da avaliação para a gestão, assim como a avaliação da implantação. As demais abordagens podem ser aprofundadas na literatura indicada, especialmente no livro introdutório de Vieira-da-Silva (2014).

A cobertura, acesso e utilização são características presentes em qualquer intervenção ou política e estão relacionadas à disponibilidade e distribuição social dos recursos dessa intervenção. A cobertura se refere à capacidade de uma intervenção em atingir os seus potenciais beneficiários. Na atenção à saúde bucal, há um indicador muito importante para avaliação da cobertura que é a Primeira Consulta Odontológica ${ }^{6}$ porque revela qual foi a proporção das pessoas moradoras em determinado território, município ou estado, por exemplo, que chegou a ser atendido em consulta odontológica programática, ou seja, com vistas a tratamento odontológico. Sua forma de cálculo é muito simples e deve ser um indicador fundamental de monitoramento da ampliação da atenção à saúde bucal pública no Brasil. Pode-se dizer que esse indicador mede a cobertura real do serviço odontológico, muito semelhante, portanto, ao conceito de utilização de serviços (cobertura real), entendida como uso e resultado da interação entre a necessidade percebida, a busca pelo serviço produtor de acesso ao interior de um sistema de saúde, que possui características próprias (políticas e organizacionais).

A acessibilidade é aqui compreendida como um dos aspectos da oferta de serviços relativo à capacidade de gerá-los e resolver as necessidades da população. Desse modo, refere-se às características dos serviços e seus recursos ca-

5 Uma análise estratégica pode ser apenas uma avaliação para a gestão que não responde a uma pergunta de pesquisa (lacuna no conhecimento).

6 A Cobertura da Primeira Consulta Odontológica é a porcentagem entre o total de indivíduos que foram ao dentista no setor público naquele ano e foram registrados como primeira consulta para tratamento em relação ao total da população daquele território, município ou estado. 
pazes de facilitar, limitar ou obstruir a utilização por seus potenciais usuários. (CUNHA; VIEIRA-DA-SILVA, 2010)

Estudos de acessibilidade a serviços de saúde bucal revelam o quanto um serviço está acessível e para que público, bem como explicitam fatores organizacionais como os relacionados aos processos gerenciais e de trabalho das equipes - modo de marcação de consulta, cumprimento de carga horária dos profissionais e clareza das metas - , e aspectos geográficos dos serviços de saúde que podem dificultar, obstruir ou facilitar o acesso a estes. Nesse sentido, persistem lacunas quanto à influência dos determinantes sociais, por um lado, e dos determinantes organizacionais e geográficos, por outro. Pode-se mesmo dizer que há uma acessibilidade social, acessibilidade organizacional e a acessibilidade geográfica.

\section{Análise e avaliação da implantação}

A implantação de uma intervenção é a transferência de uma intervenção no plano operacional, é a sua adequada operacionalização. Segundo Denis e Champagne (1997, p. 51, 54), a “[...] a análise da implantação consiste em especificar o conjunto dos fatores que influenciam os resultados obtidos após a introdução de uma intervenção". Faz uma relação entre a intervenção, seus componentes e o contexto, em comparação com a produção dos efeitos, e "[...] visa, principalmente, identificar os procedimentos implicados na produção dos efeitos de uma intervenção". Essa pode ser realizada quando a intervenção analisada é complexa e possui elementos sobre os quais o contexto pode interagir de várias formas. As possíveis teorias explicativas que influenciam a implantação de uma política podem ser aquelas de matriz sociológica de autores como Max Weber e Pierre Bourdieu, como também políticas, revelando a contribuição das relações de poder (Carlos Matus e Mário Testa). Teorias da cultura organizacional, de correntes neoinstitucionalistas também podem ser incorporadas.

A análise da implantação, ao buscar compreender os efeitos da interação, ou seja, o papel desempenhado por um conjunto de fenômenos que não a intervenção (como as concepções dos atores, da organização e outros) na determinação dos efeitos observados, aumenta a validade externa de uma avaliação. Além disso, ao discriminar a contribuição dos componentes realmente implantados do programa (grau de implantação) na produção dos efeitos, contribui também para aumentar a validade externa da pesquisa. (DENIS; CHAMPAGNE, 1997) 
Denis e Champagne (1997) apresentam três componentes para guiar a análise de implantação: a) o componente 1 propõe a análise dos determinantes contextuais do grau de implantação; b) o componente 2 que analisa a influência da variação na implantação sobre os efeitos observados; e c) o componente 3 que analisa a influência da interação entre o contexto de implantação e a intervenção sobre os efeitos observados. ${ }^{7}$

$\mathrm{Na}$ análise da implantação estes componentes trazem informações sobre os meios a serem beneficiados por uma intervenção (componente 1 e 3 ) e permitem também especificar como variações no grau de implantação agem no impacto de uma intervenção (componente 2).

\section{As avaliações participativas}

Numa perspectiva histórica, Guba e Lincoln (1989) propuseram uma classificação dos últimos cem anos do campo da avaliação em quatro gerações: a primeira geração da avaliação se caracterizaria pela mensuração, especialmente voltada para a avaliação do desempenho de escolares, no início do século XX. Nessa fase, o papel do avaliador é estencialmente técnico, cabendo ao mesmo construir e usar instrumentos de medição. A segunda geração caracterizava-se pela descrição dos processos, os padrões e pontos fortes e fracos em relação a certos objetivos declarados, considerando a necessidade de reconhecer como funcionavam os programas, como estes atingem seus resultados, diferente da geração anterior, que focalizava exclusivamente a medição de resultados. A terceira geração valorizava o julgamento, onde o avaliador continuou a exercer as funções de descrição e mensuração, sendo acrescida a função de estabelecer os méritos do programa avaliado considerando referenciais externos. Nessa pers-

Segundo Denis e Champagne (1997, p. 56-60): no componente do tipo 1, a análise desse tipo de implantação visa definir os fatores explicativos das diferenças observadas entre a intervenção planejada e a implantada, e é apropriada quando a intervenção é complexa e composta de elementos sequenciais; no componente do tipo 2 , a análise permite interpretar com mais exatidão os resultados de uma avaliação de impacto, contribuindo para distinguir os componentes de uma intervenção que facilitaram o alcance dos resultados, busca analisar a influência do grau de implantação de uma intervenção, sendo as variáveis dependentes os efeitos observados, após a sua introdução. Por ser a intervenção complexa e com pouca especificidade, o seu grau de implantação pode variar a depender do local. Então, nesse caso, pode ser possível analisar em que medida essas variações modificam os efeitos trazidos pela ação interventora; e, o componente do tipo 3 analisa a interação, sinérgica ou antagônica, entre o contexto e a intervenção em relação à produção de efeitos, tendo como objeto a generalização de uma intervenção em outros contextos. 
pectiva avaliativa, parte-se da premissa que os efeitos de um programa extrapolam os seus objetivos. (GUBA; LINCOLN, 1989)

Para esses autores, as três primeiras gerações apresentaram limitações no que se refere ao predomínio do aspecto gerencial, sem consideração à diversidade de grupos de interesse em torno do objeto avaliado; além de compromisso demasiado com o paradigma científico da investigação.

A predominância do aspecto gerencial refere-se à tendência em se atender às necessidades daqueles que encomendam ou financiam a avaliação, considerando padrões próprios e disseminação dos resultados que menosprezam ou pouco consideram outros interessados. O compromisso demasiado com o paradigma científico da investigação indica uma hegemonia de métodos quantitativos, com uma excessiva rigidez e por consequência, pouca relevância do contexto na análise das intervenções.

Em contraposição às gerações anteriores, desenvolve-se a denominada quarta geração, centrada em abordagens participativas. Estas têm como objetivo o envolvimento dos agentes no processo de avaliação, visando a capacitação e desenvolvimento dos mesmos para aprimoramento das práticas. Essa abordagem se concentra mais nas atividades meio do programa do que em seus resultados, apoiada no paradigma construtivista, em respeito à dinâmica da intervenção e dos envolvidos. Além disso, consideram uma diversidade de dados, objetivos e subjetivos, que representam múltiplas realidades e diferentes posicionamentos dos agentes envolvidos em consideração a diferentes interesses.

Nos últimos anos, a reflexão conceitual e metodológica tende a convergir sobre alguns denominadores comuns, identificando três aspectos-chave que permeiam as diversas definições: atenção pelas questões metodológicas, visualizando a avaliação como uma atividade de pesquisa; atenção com a finalidade e utilidade da avaliação, numa perspectiva de aumento do valor de uso no âmbito dos processos de tomada de decisões; reconhecimento do pluralismo de valores, que remonta à necessidade de valorização de diversos grupos de interesse.

Uma importante temática que também incorpora a discussão desses aspectos é a meta-avaliação, que se constitui como um processo de descrição, julgamento e síntese de um procedimento de avaliação, fundamentada em padrões e critérios propostos e validados pelas associações profissionais e outros organismos auditores, valorizando especialmente a qualidade e a utilidade da avaliação. (HARTZ; CONTANDRIOPOULOS, 2008) 
Uma das principais referências em termos de padrões de avaliação de programas públicos é fruto de um trabalho desenvolvido pelo Joint Committee on Standards for Educational Evaluation (JCEE). O Standards for evaluations of educational programs, projects and materials foi publicado em 1981 e revisado em 1994 para ser aplicado em outros espaços, incluindo a área da saúde. Trinta diretrizes são agrupadas em torno de quatro grandes princípios: 1) utilidade - responde às necessidades de informação dos usuários intencionais; 2) viabilidade - realista e moderada nos custos, de modo a justificar a sua realização; 3) propriedade - conduzida eticamente, respeitando o bem-estar das pessoas envolvidas na avaliação; e 4) precisão - produz informações sobre o valor dos programas e dos aspectos que determinam mérito e relevância do programa avaliado. (HARTZ; CONTANDRIOPOULOS, 2008)

A utilidade é reconhecida pelo JCEE como o atributo prioritário da avaliação. Na discussão sobre meta-avaliação, a "função da avaliação" é reconhecida como o foco prioritário, considerando os avanços no processo de institucionalização da avaliação e a necessidade desta ser valorizada e utilizada como ferramenta de governo. (HARTZ; CONTANDRIOPOULOS, 2008)

Os critérios de utilidade, conforme definido pelo JCEE (1994) são: identificação dos interessados, credibilidade do avaliador, escopo e seleção de informações, identificação de valores (perspectivas, procedimentos e justificativas usados para interpretar os resultados da avaliação devem ser cuidadosamente descritos), clareza dos relatórios de avaliação, entrega a tempo adequado e disseminação dos relatórios e impacto da avaliação.

A utilidade dos resultados da avaliação é amplamente valorizada por Patton (1997), o qual propõe uma abordagem avaliativa que tem como foco a utilização dos resultados (utilization-focused evaluation). A abordagem parte da premissa que as avaliações deveriam ser julgadas por sua utilidade, sendo que a avaliação deveria ser desenhada e desenvolvida considerando como as pessoas vivenciarão o processo de avaliação e a sua aplicação. O autor discute a avaliação como dispositivo de mudança, a partir da incorporação dos principais grupos de interesse e valorização das possibilidades de utilização dos resultados pelos envolvidos na reformulação de suas práticas. A avaliação com foco na utilização considera que existem maiores possibilidades que os participantes utilizem as avaliações se estes compreendem e se sentem donos do processo de avaliação e de seus resultados. Além disso, durante o processo de avaliação, é possível reforçar a utilidade pretendida e "preparar o terreno" para o uso. Segundo Pat- 
ton (1997), a avaliação com foco na utilização inicia-se com a premissa de que avaliações devem ser julgadas por sua verdadeira utilidade; para tanto, os avaliadores devem facilitar o planejamento e a implementação da avaliação com cuidadosa consideração não em abstrações, mas sim levando-se em conta as expectativas de pessoas reais no mundo real, consequentemente, a ênfase da avaliação com foco na utilização é na intenção de uso revelada pelos usuários intencionais.

\section{Estudos no Brasil de avaliação da atenção em saúde bucal}

Como subespaço ao interior da saúde coletiva, imagina-se que a produção de conhecimento em torno da avaliação em saúde bucal seja ainda mais incipiente que na sua subárea de origem que é o próprio subespaço da avaliação na saúde coletiva. Na área da saúde bucal, a avaliação em saúde pode subsidiar a tomada de decisão, o redirecionamento das políticas, programas e serviços, mas tem como desafio realizar contínuo monitoramento dos serviços através do uso de indicadores, tanto dos serviços de saúde como do estado de saúde da população. O monitoramento dos indicadores do estado de saúde bucal da população brasileira tem sido denominado por Goes e colaboradores (2012) de vigilância em saúde bucal. Entre eles, destacam-se os índices já aceitos internacionalmente como o CPO-D, a ceo-d para tendências da prevalência e severidade da cárie dental com diferentes análises quanto à participação da composição percentual dos seus componentes. Indicadores de doença periodontal como o IPC e o PIP, índice de Dean para fluorose. Para o câncer bucal, coeficientes de mortalidade por sexo e faixa etária podem ser monitorados. ${ }^{8}$

Colussi e Calvo (2012) publicaram revisão da literatura sobre avaliação da atenção em saúde bucal no Brasil. As autoras encontraram 23 estudos de avaliação do serviço ou da assistência em saúde bucal, sendo 15 artigos e 8 dissertações, até o ano de 2010, com grande diversidade metodológica.

$8 \quad \mathrm{O}$ CPO-D se refere à média de dentes permanentes cariados. perdidos e restaurados por grupo etário, bem como o ceo-d, como média de dentes decíduos cariados, perdidos por cárie e restaurados por grupo etário. Revelam a pevalência quando são apresentados em termos de proporção de indivíduos livres de cárie e também revelam a severidade, quando são apresentados em média por grupo etário. O IPC é um indicador que revela a proporção de indivíduos ou sextantes em determinado grupo com gengiva saudável, com sangramento gengival com bolsa periodontal leve ou severa. O índice de Dean revela a prevalência de fluorose dentária. Ele mede a proporção de indivíduos com fluorose muito leve, leve, moderada e severa. Para maior aprofundamento nos indicadores do estado de saúde bucal da população, ver capítulo 2. 
Com o objetivo de verificar a continuidade das publicações sobre avaliação em saúde bucal no período de 2011 a 2015, este capítulo complementou a busca de artigos na base de dados Scielo, com as palavras chaves "avaliação", "odontologia" e "saúde bucal". Nessa busca, foram encontrados 57 artigos, dos quais 9 foram considerados "estudos de avaliação", conforme critérios utilizados por Colussi e Calvo (2012), ou seja, aqueles que apresentavam a palavra "avaliação" no título do trabalho, nas palavras-chave, ou aqueles que utilizaram o verbo "avaliar" nos objetivos ou metodologia do trabalho - e tratavam da avaliação do serviço ou da assistência odontológica no país (Quadro 3). As autoras apontaram que a maioria dos trabalhos é do tipo avaliação externa, provenientes de pesquisas acadêmicas. Obviamente, a publicação de estudos de avaliação rotineira dos serviços não é simples em revistas indexadas, o que dificulta mensurar em que medida a avaliação nessa área tem sido institucionalizada. Outra questão problemática tem sido a não explicitação de juízo de valor referente ao objeto "avaliado", o que é contraditório com o conceito já compartilhado de formulação clara desse julgamento por qualquer estudo dessa natureza. $\mathrm{Na}$ revisão realizada por Colussi e Calvo (2012), chamou atenção também que, dentre os atributos mais avaliados, estavam a satisfação dos usuários em 8 dos 23 estudos (34,8\%), e o acesso em três estudos (13,1\%). Conforme foi ressaltado anteriormente, pesquisas avaliativas, produto da formação acadêmica, tem maior possibilidade de publicação em periódicos indexados. Provavelmente, estudos de avaliação de intervenções, realizadas rotineiramente nos serviços não foram captados pelas limitações da própria fonte de dados, que estão revistas com grande filtro nas publicações. Concordamos com a necessidade de mapear as práticas avaliativas rotineiras nos serviços odontológicos públicos, inclusive, pensando no processo desencadeado pelo Programa para Melhoria do Acesso e Qualidade da Atenção Básica (PMAQ-AB) e Programa para Melhoria do Acesso e Qualidade dos Centros de Especialidades Odontológicas (PMAQ-CEO), que possibilitaram essa capilaridade. Essa prática avaliativa como fenômeno social interno aos serviços de saúde é muito importante e precisa ser melhor estudada, tanto no sentido das avaliações desencadeadas a partir do monitoramento dos principais indicadores da atenção à saúde bucal quanto através das induções advindas das políticas do poder executivo, como foi o caso recente do PMAQ. Observa-se ainda pouca produção em saúde bucal no que se refere aos estudos de avaliação da qualidade da atenção odontológica. Há iniciativa com o PMAQ e os resultados do PMAQ-AB no país apontam que na 
maioria das subdimensões os desempenhos das ações de saúde bucal estão na mediana ou muito abaixo da média, são desafios importantes, tanto no acesso quanto na organização e qualidade do processo de trabalho.

\section{Quadro 3 - Estudos de avaliação do serviços de atenção à saúde bucal no Brasil até 2015, a partir dos estudos selecionados de Colussi e Calvo até 2010 (2012)}

(continua)

\begin{tabular}{|c|c|c|c|}
\hline $\begin{array}{l}\text { Autor(es) e } \\
\text { natureza da } \\
\text { publicação }\end{array}$ & Abordagem & $\begin{array}{l}\text { Natureza } \\
\text { dos } \\
\text { dados }\end{array}$ & Atributos da avaliação \\
\hline $\begin{array}{c}\text { Matos et al., } 2002 \\
\text { Centro de Pesquisas } \\
\text { René Rachou da } \\
\text { Fundação Oswaldo Cruz. } \\
\text { Minas Gerais }\end{array}$ & Quantitativa & Primários & $\begin{array}{l}\text { Avaliação da desigualdade na utilização de } \\
\text { procedimentos restauradores e preventivos em serviços } \\
\text { odontológicos privados, públicos e de sindicato. } \\
\text { Satisfação do usuário. }\end{array}$ \\
\hline $\begin{array}{l}\text { Barros, Bertoldi, } 2002 \\
\text { Universidade Federal } \\
\text { de Pelotas -Rio Grande } \\
\text { do Sul }\end{array}$ & Quantitativa & Secundários & $\begin{array}{l}\text { Utilização e acesso a serviços odontológicos } \\
\text { públicos e privados, e diferenciais entre os estratos } \\
\text { socioeconômicos. }\end{array}$ \\
\hline $\begin{array}{l}\text { Mialhe, Oliveira, Silva, } \\
\qquad 2006 \\
\text { UNICAMP - São Paulo }\end{array}$ & Quantitativa & Primários & $\begin{array}{c}\text { Acesso e satisfação dos usuários aos serviços } \\
\text { odontológicos públicos e privados em uma comunidade } \\
\text { rural. }\end{array}$ \\
\hline $\begin{array}{c}\text { Andrade, Ferreira, } 2006 \\
\text { UFMG- Minas Gerais }\end{array}$ & $\begin{array}{l}\text { Quantitativa e } \\
\text { qualitativa }\end{array}$ & Primários & $\begin{array}{l}\text { Satisfação do usuário sobre a atuação da equipe de } \\
\text { saúde da família em um município. }\end{array}$ \\
\hline $\begin{array}{c}\text { Souza, Roncalli, } 2007 \\
\text { UFRN - Natal }\end{array}$ & $\begin{array}{l}\text { Quantitativa } \\
\text { e qualitativa }\end{array}$ & Primários & $\begin{array}{c}\text { Implantação do modelo assistencial do PSF com foco no } \\
\text { acesso, organização do processo de trabalho e lógica de } \\
\text { programação. }\end{array}$ \\
\hline $\begin{array}{l}\text { Chaves, Silva, } 2007 \\
\text { ISC/ UFBA- Bahia }\end{array}$ & Quantitativa & $\begin{array}{l}\text { Primários e } \\
\text { secundários }\end{array}$ & $\begin{array}{l}\text { Grau de implantação da atenção à saúde bucal em dois } \\
\text { municípios a partir da imagem-objetivo da política. }\end{array}$ \\
\hline $\begin{array}{l}\text { Fadel, Sandrini, Zardo, } \\
\qquad 2007 \\
\text { UEPG- Paraná }\end{array}$ & $\begin{array}{l}\text { Quantitativa e } \\
\text { qualitativa }\end{array}$ & Primários & $\begin{array}{l}\text { Satisfação dos usuários dos serviços odontológicos na } \\
\text { ESF, incluindo acesso e relação com a equipe. }\end{array}$ \\
\hline $\begin{array}{l}\text { Emmi, Barroso, } 2008 \\
\text { Universidade Federal do } \\
\text { Pará. Pará. }\end{array}$ & Quantitativa & Primários & $\begin{array}{l}\text { Satisfação do usuário quanto às ações de saúde bucal } \\
\text { desenvolvidas. }\end{array}$ \\
\hline
\end{tabular}




\section{Quadro 3 - Estudos de avaliação do serviços de atenção à saúde bucal no Brasil até 2015, a partir dos estudos selecionados de Colussi e Calvo até 2010 (2012)}

(continuação)

\begin{tabular}{|c|c|c|c|}
\hline $\begin{array}{l}\text { Martelliet al., } 2008 \\
\text { Centro de Pesquisas } \\
\text { Aggeu Magalhães, } \\
\text { Fundação Oswaldo Cruz } \\
\text { - Pernambuco. }\end{array}$ & $\begin{array}{l}\text { Quantitativa e } \\
\text { qualitativa }\end{array}$ & Primários & $\begin{array}{l}\text { Implantação do modelo de atenção à saúde bucal, } \\
\text { incluindo a qualificação dos profissionais, mudança do } \\
\text { perfil assistencial e referência e contrarreferência. }\end{array}$ \\
\hline $\begin{array}{l}\text { Ribeiro-Sobrinho, Souza, } \\
\text { Chaves, } 2008 \\
\text { ISC/UFBA- Bahia }\end{array}$ & Quantitativa & Secundários & Cobertura de um serviço odontológico. \\
\hline $\begin{array}{l}\text { Nickel, Calvo, Caetano, } \\
2009 \\
\text { UFSC - Santa Catarina }\end{array}$ & Quantitativa & $\begin{array}{l}\text { Primários e } \\
\text { secundários }\end{array}$ & $\begin{array}{l}\text { Atenção em saúde bucal na atenção básica municipal } \\
\text { com proposta de indicadores de avaliação para a gestão. }\end{array}$ \\
\hline $\begin{array}{c}\text { Figueiredo, Góes, } 2009 \\
\text { Universidade de } \\
\text { Pernambuco }\end{array}$ & Quantitativa & Secundários & Implantação/desempenho dos CEO. \\
\hline $\begin{array}{l}\text { Frazão, Marques, } 2009 \\
\text { Universidade Católica de } \\
\text { Santos -São Paulo }\end{array}$ & Quantitativa & Primários & $\begin{array}{l}\text { Efeito/impacto do Programa Agentes Comunitários de } \\
\text { Saúde na promoção da saúde bucal. }\end{array}$ \\
\hline $\begin{array}{l}\text { Reis et al., } 2009 \\
\text { FUNORTE -Minas Gerais; } \\
\text { UFBA -Bahia. }\end{array}$ & Qualitativa & Primários & $\begin{array}{l}\text { Satisfação dos usuários sobre o serviço de saúde bucal } \\
\text { municipal. }\end{array}$ \\
\hline $\begin{array}{l}\text { Lima, Cabral, } \\
\text { Vasconcelos, } 2010 \\
\text { UFPE- Pernambuco }\end{array}$ & Quantitativa & $\begin{array}{l}\text { Primários e } \\
\text { secundários }\end{array}$ & Satisfação dos usuários dos CEO. \\
\hline $\begin{array}{l}\text { Chaves et al., } 2011 \\
\text { ISC/ UFBA - Bahia. }\end{array}$ & $\begin{array}{l}\text { Qualitativa e } \\
\text { Quantitativa }\end{array}$ & $\begin{array}{l}\text { Primários e } \\
\text { Secundários }\end{array}$ & $\begin{array}{l}\text { Utilização dos serviços odontológicos especializados de } \\
\qquad \text { CEO e fatores relacionados. }\end{array}$ \\
\hline $\begin{array}{c}\text { Pereira et al., } 2012 \\
\text { PUC -Minas Gerais;UFRN- } \\
\text { Natal; } \\
\text { UFBA, Bahia; CRO- } \\
\text { Maranhão }\end{array}$ & Quantitativa & Primários & $\begin{array}{l}\text { Efeito da ESF sobre a saúde bucal na população do } \\
\text { Nordeste do Brasil de } 12 \text { municípios com mais de } 100 \\
\text { mil habitantes. (implantação e modelo assistencial?) }\end{array}$ \\
\hline $\begin{array}{l}\text { Góes et al., } 2012 \\
\text { UFPE- Pernambuco }\end{array}$ & Quantitativa & $\begin{array}{l}\text { Primários e } \\
\text { Secundários }\end{array}$ & $\begin{array}{l}\text { Implantação dos CEO com base na produção } \\
\text { ambulatorial e satisfação da equipe profissional. }\end{array}$ \\
\hline
\end{tabular}




\section{Quadro 3 - Estudos de avaliação do serviços de atenção à saúde bucal no Brasil até 2015, a partir dos estudos selecionados de Colussi e Calvo até 2010 (2012)}

(conclusão)

\begin{tabular}{|c|c|c|c|}
\hline $\begin{array}{l}\text { Bulgareliet al., } 2013 \\
\text { UNICAMP -São Paulo }\end{array}$ & Quantitativa & Secundários & $\begin{array}{l}\text { Efeito na integralidade dos diferentes modelos de } \\
\text { atenção básica em saúde bucal (ESF e UBS) em relação } \\
\text { à referência à atenção especializada. }\end{array}$ \\
\hline $\begin{array}{l}\text { Giudice, Pezzato e } \\
\text { Botazzo, } 2013 \\
\text { UNICAMP - São Paulo }\end{array}$ & Qualitativa & Primários & $\begin{array}{l}\text { Avaliação do processo de trabalho da ESF e reflexões a } \\
\text { partir do PMAQ-AB. }\end{array}$ \\
\hline $\begin{array}{l}\text { Bulgareliet al., } 2014 \\
\text { UNICAMP - São Paulo. }\end{array}$ & Quantitativa & Secundários & $\begin{array}{l}\text { Efeito dos modelos de atenção básica (ESF ou UBS) em } \\
\text { relação às necessidades de saúde bucal da população no } \\
\text { acesso e conclusão de tratamento odontológico. }\end{array}$ \\
\hline $\begin{array}{l}\text { Lino et al., } 2014 \\
\text { UFMG- Minas Gerais }\end{array}$ & Quantitativa & Secundários & $\begin{array}{l}\text { Implantação da atenção especializada com base na } \\
\text { produção ambulatorial municipal. }\end{array}$ \\
\hline $\begin{array}{c}\text { Pimentel et al., } 2014 \\
\text { Centro de Pesquisas } \\
\text { Aggeu Magalhães da } \\
\text { FIOCRUZ - Pernambuco }\end{array}$ & Quantitativa & Secundários & $\begin{array}{l}\text { Assistência à saúde bucal no âmbito estadual. Utilizou } \\
\text { indicadores de saúde bucal. }\end{array}$ \\
\hline $\begin{array}{l}\text { Magalhães et al., } 2015 \\
\text { UFPE - Pernambuco. }\end{array}$ & Quantitativa & Primários & $\begin{array}{l}\text { Qualidade dos serviços ofertados nos CEO na } \\
\text { perspectiva da satisfação dos usuários. }\end{array}$ \\
\hline
\end{tabular}

Fontes: adaptado de Colussi e Calvo (2012) e complementado com artigos do Scielo entre 2010 e 2015.

Na releitura desses trabalhos selecionados por Colussi e Calvo (2012), bem como nos trabalhos posteriores, destacou-se a diversidade e confusão conceitual quanto aos atributos da avaliação, bem como a não explicitação de conceitos. Exemplos disso foram o uso do termo qualidade, desempenho e eficiência. Há um número de estudos que poderiam ser classificados como estudos de avaliação de processo ou implantação, ainda que não tenha explicitado exatamente esse termo no método, já que estes estavam voltados para avaliar o quanto foi adequadamente operacionalizada a política ou atenção à saúde bucal. Desempenho como sinônimo de implantação foi muito comum, ou seja, a ideia de operacionalização adequada de uma intervenção vista como desempenho. Exemplos disso foram os estudos de Figueiredo e Goes (2009), Goes e colaboradores (2012), Lino e colaboradores (2014), Martelli e colaboradores (2008), Souza e Roncalli (2007). A avaliação da satisfação do usuário predominou, mas não se pode considerar a qualidade do serviço a partir dessa satisfação. Além disso, um mesmo estudo analisava mais de um atributo, como acesso e satisfa- 
ção. No Quadro 3, adaptado de Colussi e Calvo (2012), estão apresentados 24 artigos, dos quais 15 são aqueles já sistematizados por essas autoras e nove artigos novos publicados do período entre 2011 e 2015. Observou-se predominância de estudos quantitativos (60,9\%), seguidos pelos de abordagem mista quali-quanti $(30,4 \%)$. Chama a atenção a existência de apenas um estudo somente qualitativo nessa área. Há predomínio do uso de dados primários $(60,9 \%)$ e primários e secundários (21,7\%). É curioso notar grande esforço na coleta de dados (dados primários locais), com análise quantitativa apenas.

Giudice, Pezzato e Botazzo (2013), único estudo com abordagem participativa de quarta geração, avaliaram o processo de trabalho em uma Equipe de Saúde da Família de Campinas, São Paulo, através do uso da metodologia da pesquisa qualitativa (entrevistas semiestruturadas - com usuários - e grupos focais - com profissionais de saúde). Os autores destacam que este modelo de atenção conseguiu introduzir novos saberes nas práticas dos profissionais, contribuiu para um maior envolvimento intraequipe e com os usuários e incrementou o compromisso com a promoção de saúde das famílias. Entretanto, cabe destacar que esse estudo avaliou uma Equipe de Saúde da Família (ESF) diferenciada, com as equipes ampliadas - que incluem pediatra e ginecologista, além de contar com o matriciamento de outros profissionais, como psiquiatra, psicólogo, terapeuta ocupacional e nutricionista, dentre outros. Além disso, houve uma capacitação, seguindo os protocolos de implantação do Programa de Saúde da Família (PSF) para toda a rede municipal, com cerca de 180 horas-aula a partir do método paideia.

Bulgareli e colaboradores (2013) reforçam que o impacto das ações de saúde bucal na ESF tem evidente progresso em relação aos princípios de universalidade, equidade e integralidade, sendo esta análise importante na avaliação da resolutividade da atenção básica. Ainda que o modelo baseado na Estratégia Saúde da Família (ESF) possua dificuldade em prover atendimento integral, no acesso à endodontia (uma das maiores necessidades odontológicas em especialidade de forma geral), a saúde da família apresentou melhores resultados que a Unidade Básica de Saúde (UBS) tradicional. Os autores também verificaram que na UBS, a população adscrita na área de abrangência é bem superior à da ESF, o que dificulta desde o acesso geográfico dos pacientes para a unidade de saúde até o reconhecimento de toda a clientela do território, dessa maneira, o vínculo é menor e há pouca adesão ao tratamento. (BULGARELI et al., 2013). Bulgareli e colaboradores (2014) em outra publicação a partir do mesmo estu- 
do, avaliaram também a resolutividade das ações de saúde bucal desenvolvidas na atenção básica em modelos de atenção distintos (ESF ou UBS). Os autores concluíram que o modelo baseado na saúde da família apresentou melhor resultado no acesso e conclusão de tratamento odontológico.

Um estudo de avaliação da atenção secundária em saúde bucal, com caráter avaliativo normativo, utilizando dados da produção ambulatorial dos CEO do país registrados nos Sistemas de Informação Ambulatorial (SIA/SUS), em 2007, e dados primários, de 10\% dos serviços implantados, observou que, na maioria das regiões, houve dificuldade no cumprimento das metas relativas à quantidade de procedimentos por especialidade, sendo a região Norte com menor percentual de cumprimento de metas. Foi evidenciada a necessidade de revisão no marco legal para a implantação dos CEO e definições de novos padrões e cumprimento de metas para avaliação e monitoramento de tais serviços. (GOES et al., 2012) Outro estudo avaliou a atenção odontológica especializada no estado de Minas Gerais, também através da produção ambulatorial registrada no SIA/ SUS. (LIMA; CABRAL; VASCONCELOS, 2010) Todas as unidades de saúde que realizavam procedimentos considerados especializados nas áreas de endodontia, periodontia e cirurgia pela PNSB foram incluídas na análise. Apesar da maioria dos procedimentos ter sido realizada em UBS, os resultados do estudo indicaram que os CEO são mais eficientes na execução de procedimentos especializados em saúde bucal. Todavia, ainda que o desempenho dos CEO tenha sido mais favorável, grande parte desses serviços não atingiram as metas estabelecidas pelo Ministério da Saúde. (LINO et al., 2014)

Pimentel e colaboradores (2014) analisaram a assistência à saúde bucal no estado de Pernambuco, com base em seus indicadores (cobertura de primeira consulta odontológica programática; cobertura da ação coletiva Escovação Dental Supervisionada; média de procedimentos odontológicos básicos individuais e proporção de exodontias em relação às ações odontológicas básicas individuais) segundo as variáveis porte populacional, proporção da população cadastrada e relação entre as ESF e ESB. Os resultados mostraram que municípios de grande porte apresentaram menores valores para proporção de exodontias. Outro aspecto encontrado foi que, quanto maior a cobertura e quando a relação entre as equipes era um para um, mais favoráveis eram os indicadores.

Também no estado de Pernambuco, Magalhães e colaboradores (2015) realizaram estudo com o objetivo de avaliar os serviços ofertados nos CEO, na perspectiva da satisfação dos usuários. A análise dos dados revelou que os usuários 
estão satisfeitos com a qualidade dos serviços prestados nos CEO do estado. É importante destacar que, na dimensão da eficiência, os autores consideraram a relação custo-benefício no sentido de que "valeu a pena" a utilização dos serviços de saúde bucal, mesmo diante de todas as dificuldades/barreiras que eles possam ter enfrentado para acessar o serviço. Aqui, cabe uma ressalva do uso do termo "qualidade" no senso comum. A satisfação do usuário com serviço é uma dimensão distinta da dimensão da sua qualidade, considerando este ou no sentido amplo (sete pilares da qualidade de Donabedian) ou no sentido estrito como a qualidade técnico-científica, como o uso adequado da evidência técnica e científica para o cuidado.

Estudo de Chaves e colaboradores (2011) analisou a oferta e utilização de procedimentos em CEO na Bahia, tendo como foco a relação entre a oferta potencial como disponibilidade de recursos em horas de trabalho e a utilização real dessa oferta na produção ambulatória desses serviços no sistema de informação ambulatorial. Houve uma baixa taxa de utilização conforme os padrões propostos pela Portaria GM n. ${ }^{0} 1.101 / 2002$ e pela consulta aos especialistas, ou seja, a oferta disponível está, de fato, sendo subutilizada para um tipo de serviço estencial na garantia da integralidade da atenção à saúde bucal. Nesse sentido, a baixa taxa de utilização em algumas especialidades pode ser reveladora de problemas de gestão do serviço, como o não monitoramento de padrões e metas de produção por especialidade e a falta dos pacientes, que não são substituídos. Além disso, houve conflitos importantes na integração entre a atenção básica e atenção especializada, tanto na pertinência na indicação para esse nível de atenção, bem como na referência do paciente sem a devida promoção de saúde bucal e procedimentos básicos, funções da atenção primária.

\section{Considerações finais}

Avaliação da política, através do uso de indicadores de produção ambulatorial oriundos de base de dados secundárias, traz elementos de resultados e implantação desses serviços públicos odontológicos e são úteis para a gestão, sobretudo para organização da saúde bucal no âmbito municipal. Contudo, este não analisa outros atributos do serviço e da própria política, que devem ser avaliados a partir das demandas dos gestores e beneficiários, bem como dos interesses daqueles que produzem conhecimento na temática.

O espaço da avaliação em saúde bucal carece de estudos que contemplem análises com abordagens metodológicas mistas e que incluam teorias sociais 
explicativas dos fenômenos observados, e possam assim avançar na contribuição acadêmica sobre a implementação da PNSB e para a prática política cotidiana daqueles que militam na área. Outra questão importante é em que medida as avaliações serão utilizadas na tomada de decisão dos gestores e dos executores. Problemática também relevante no espaço da avaliação em saúde que merecerá estudos posteriores para seu acompanhamento. Nesse caso, a aposta em estratégias participativas com a devida cientificidade é um caminho possível.

\section{Referências}

ANDRADE K. L. C.; FERREIRA, E. F. Avaliação da inserção da odontologia no Programa de Saúde da Família de Pompeu (MG): a satisfação do usuário. Ciência \& Saúde Coletiva, Rio de Janeiro, v. 11, n. 1, p. 123-130, 2006.

BARROS, A. J. D.; BERTOLDI, A. D. Desigualdades na utilização e no acesso a serviços odontológicos: uma avaliação em nível nacional. Ciência \& Saúde Coletiva, Rio de Janeiro, v. 7, n. 4, p. 709-17, 2002.

BROUSSELlE, A. et al. (Org.). Avaliação, conceitos e métodos. Rio de Janeiro: Ed. Fiocruz, 2011.

BULGARELI, J. V. et al . Informações da atenção secundária em Odontologia para avaliação dos modelos de atenção à saúde. Revista de Odontologia da UNESP, v. 42, n. 4, p. 229-236, 2013 .

BULGARELI, J. et al. A resolutividade em saúde bucal na atenção básica como instrumento para avaliação dos modelos de atenção. Ciência \& Saúde Coletiva, Rio de Janeiro, v. 19, n. 2, p. 383-391, 2014

CHAMPAGNE, F. et al. A Avaliação no Campo da Saúde: conceitos e métodos. In: BROUSSELlE, A. et al (Org.) Avaliação, conceitos e métodos. Rio de Janeiro: Ed. FIOCRUZ, 2011. p. 41-60.

CHAVES, S. C. L. et al. Avaliação da oferta e utilização de Especialidades Odontológicas em Serviços Públicos de Atenção Secundária na Bahia, Brasil. Cadernos de Saúde Pública, Rio de Janeiro, v. 27, n. 1, p. 143-154, 2011.

CHAVES, S. C. L.; SILVA, L. M. V. da. Atenção à saúde bucal e a descentralização da saúde no Brasil: estudo de dois casos exemplares no Estado da Bahia. Cadernos de Saúde Pública, Rio de Janeiro, v. 23, n. 5, p. 1119-31, 2007.

CHEN, H. T. Practical Program Evaluation: assessing and improving planning, implementation, and effectiveness. Thousand Oaks, CA: Sage Publications, 2005.

COHEN, E.; FRANCO, R. Avaliação de projetos sociais. Petrópolis, RJ: Vozes, 1993. 
COLUSSI, C. F.; CALVO, M. C. M. Avaliação da atenção em Saúde Bucal no Brasil: uma revisão da literatura. Saúde e Transformação Social., Florianópolis, v. 3, p. 92-100, jan. 2012. CONTANDRIOPOULOS, A. P. et al. Avaliação na área da saúde: conceitos e métodos. In: HARTZ, Z. M. A. (Ed). Avaliação em saúde: dos modelos conceituais à prática na análise da implantação de programas. Rio de Janeiro: Ed. Fiocruz, 1997. p. 29-48.

CONTANDRIOPOULOS, A. P. et al. Avaliação na área da saúde: conceitos e métodos. In: HARTZ,Z. M. A. Avaliação em Saúde. Rio de Janeiro: Ed. Fiocruz, 1997.

CUNHA, A. B. O.; SILVA, L. M. V. Acessibilidade aos serviços de saúde em um município do Estado da Bahia, Brasil, em gestão plena do sistema. Cadernos de Saúde Pública, , Rio de Janeiro, v. 26, n. 4, p. 725-737, 2010.

DENIS, J. L.; CHAMPAGNE, F. Análise da implantação de programas. In: HARTZ, Z. M. A. (Ed). Avaliação em saúde: dos modelos conceituais à prática na análise da implantação de programas. Rio de Janeiro: Ed. FIOCRUZ, 1997. p. 49-88.

EMMI, D. T.; BARROSO, R. F. F. Avaliação das ações de saúde bucal no Programa Saúde da Família no distrito de Mosqueiro, Pará. Ciência \& Saúde Coletiva, Rio de Janeiro,, v. 13, n. 1, p. 35-41, 2008.

FADEL, C. B.; SANDRINI, J. C.; ZARDO, L. N. Avaliação do perfil e grau de satisfação dos usuários dos serviços odontológicos na Estratégia de Saúde da Família, na zona rural do município de Castro/PR. Publ. UEPG Ci. Biol. Saúde, Ponta Grossa, v. 13, n. 3/4, p. 59-66, 2007.

FIGUEIREDO, N.; GOES, P. S. A. Construção da atenção secundária em saúde bucal: um estudo sobre os Centros de Especialidades Odontológicas em Pernambuco, Brasil. Cadernos de Saúde Pública, , Rio de Janeiro, v. 25, n. 2, p. 259-267, 2009.

FRAZÃO, P.; MARQUES, D. Efetividade de programa de agentes comunitários na promoção da saúde bucal. Revista de Saúde Pública., v. 43, n. 3, p. 463-471, 2009.

FURTADO, J. P.; SILVA, L. M. V. da. A avaliação de programas e serviços de saúde no Brasil enquanto espaço de saberes e práticas. Cadernos de Saúde Pública, Rio de Janeiro, v. 30, n. 12, p. 2643-2655, 2014.

GIUDICE, A. M. P.; PEZZATO, L. M.; BOTAZZO, C. Práticas avaliativas: reflexões acerca da inserção da saúde bucal na Equipe de Saúde da Família. Saúde em Debate. Rio de Janeiro, v. 37, n. 96, p. 32-42, 2013.

GOES, P. S. A. de et al. Avaliação da atenção secundária em saúde bucal: uma investigação nos centros de especialidades do Brasil. Caderno de Saúde Pública, Rio de Janeiro, v. 28, supl., p. s81-s89, jan. 2012 .

GUBA, E.; LINCOLN, Y. Fourth generation evaluation. Newsbury Park: Sage, 1989.

HARTZ, Z. M. A. (Org.). Avaliação em saúde: dos modelos conceituais à prática na análise da implantação de programas. 20. ed. Rio de Janeiro: Ed. FIOCRUZ, 1997. 
HARTZ, Z. M. A.; CONTANDRIOPOULOS, A. P. Do quê ao para quê da meta- avaliação em saúde. In: HARTZ, Z. M. A.; FELIZBERTO, E.; SILVA, L. M. V. da. (Org.). Meta - Avaliação da Atenção Básica à Saúde: teoria e prática. Rio de Janeiro: Ed. FIOCRUZ, 2008.

LEVITON, L. C.; HUGHES, E. F. X. Research on the utilization of evaluations: a review and synthesis. Evaluation Review., v. 5, p. 525-547, 1981.

LIMA, A. C. S.; CABRAL, E. D.; VASCONCELOS, M. M. V. B. Satisfação dos usuários assistidos nos Centros de Especialidades Odontológicas do Município do Recife, Pernambuco, Brasil. Cadernos de Saúde Pública, Rio de Janeiro, v. 26, n. 5, p. 991-1002, 2010.

LINO, P. A. et al. Análise da atenção secundária em saúde bucal no estado de Minas Gerais, Brasil. Ciência \& Saúde Coletiva, Rio de Janeiro,, v. 19, n. 9, p. 3879-3888, 2014.

MAGALHÃES, B. G. et al. Avaliação da qualidade dos serviços prestados pelos Centros de Especialidades Odontológicas: visão dos usuários. Cadernos Saúde Coletiva, Rio de Janeiro, v. 23 , n. 1, p. 76-85, 2015 .

MARTELLI, P. J. de L. et al . Análise do modelo de atenção à saúde bucal em municípios do estado de Pernambuco. Ciência \& Saúde Coletiva, Rio de Janeiro, v. 13, n. 5, p. 1669-1674, 2008 .

MATOS, D. L. et al. Projeto Bambuí: avaliação de serviços odontológicos privados, públicos e de sindicato. Revista de Saúde Pública, São Paulo, , v. 36, n. 2, p. 237-243, abr. 2002.

MATUS, C. El PES en la practica. Caracas: Fundación Altadir, 1994.

MEDINA, M. G. et al.Uso de modelos teóricos na avaliação em saúde: aspectos conceituais e operacionais. In: HARTZ, Z. M. A.; SILVA, L. M. V. da. (Org.). Avaliação em saúde: dos modelos conceituais à prática na análise de programas e sistemas de saúde. Salvador: EDUFBA; Rio de Janeiro: Ed. FIOCRUZ. 2005. p. 41- 63.

MIALHE, F. L.; OLIVEIRA, C. S. R.; SILVA, D. D. Acesso e avaliação dos serviços de saúde bucal em uma localidade rural da região sul do Brasil. Arquivos de Ciências da Saúde da Unipar, v. 10, n. 3, p.145-149, set./dez. 2006.

NICKEL, D. A.; CALVO, M. C. M.; CAETANO, J. C. Modelo de avaliação da atenção em saúde bucal. Pesquisa Brasileira em Odontopediatria e Clínica Integrada, João Pessoa, . v. 9, n. 3, p. 373-379, 2009.

PEREIRA, C. R. S. et al. Impacto da Estratégia Saúde da Família sobre indicadores de saúde bucal: análise em municípios do Nordeste brasileiro com mais de 100 mil habitantes.

Cadernos de Saúde Pública, Rio de Janeiro, v. 28, n. 3, p. 449-462, 2012.

PIMENTEL, F. et al. Análise dos indicadores de saúde bucal do Estado de Pernambuco: desempenho dos municípios segundo porte populacional, população cadastrada no Sistema de Informação da Atenção Básica e proporção na Estratégia Saúde da Família. Cadernos Saúde Coletiva, Rio de Janeiro, v. 22, n. 1, p. 54-61, 2014.

PATTON, M. Q. Utilization-focused evaluation.The new century text.Thousands OaksLondon- New Delhi: SAGE Publications, 1997. 
PATTON, M. Q. Qualitative Research \& Evaluation Methods.Thousands Oaks: SAGE Publications, 2002.

REIS, C. et al. Avaliação do serviço de saúde bucal no município de Grão Mogol, Minas Gerais, Brasil: "a voz do usuário". Ciência \& Saúde Coletiva, Rio de Janeiro, , v. 14, n. 4, p. 1287-1295, 2009.

RIBEIRO-SOBRINHO, C.; SOUZA, L. E. P. F.; CHAVES, S. C. L. Avaliação da cobertura do Serviço Odontológico da Polícia Militar da Bahia em Salvador, Bahia, Brasil. Cadernos Saúde Coletiva, Rio de Janeiro, v. 24, n. 2, p. 295-302, 2008.

ROSSI, P. H.; FREEMAN, H. E. Evaluation: a systematic approach. 5th ed. Newbury Park: Sage, 1993.

ROSSI, T. R. A; CHAVES, S. C. L. Implementação da Atenção Especializada em Saúde Bucal em dois municípios na Bahia/Brasil. Saúde debate, Rio de Janeiro, v. 39, n. spe, p.196206, dez. 2015. Diponível em: <http://dx.doi.org/10.5935/0103-1104.2015So05186>. Acesso em: 16 jun. 2016.

SILVA, L. M. V. da.; FORMIGLI, V. L. A. Avaliação em saúde: limites e perspectivas. Cadernos de Saúde Pública, Rio de Janeiro, v. 10, n. 1, p. 80-91, 1994.

SILVA, L. M. V. da. Conceitos, Abordagens e Estratégias para Avaliação em Saúde. In: SILVA, L. M. V. da.; HARTZ, Z. M. A. Avaliação em saúde: dos modelos teóricos à prática na avaliação de programas e sistemas de saúde. Salvador: EDUFBA; Rio de Janeiro: Ed. FIOCRUZ, 2005. p. 15-39.

SOUZA, C. Estado da Arte da Pesquisa em Políticas Públicas. In: HOCHMAN, G.; ARRETCHE, M.; MARQUES, E. Políticas públicas no Brasil. Rio de Janeiro: Ed. FIOCRUZ, 2007.

SOUZA, T. M. S.; RONCALLI, A. G. Saúde bucal no Programa Saúde da Família: uma avaliação do modelo assistencial. Cadernos de Saúde Pública, Rio de Janeiro, v. 23, n. 11, p. 2727-2739, 2007.

VIEIRA-DA-SILVA, L. M.. Avaliação de Políticas e Programas de Saúde. Temas em Saúde Coletiva. Rio de Janeiro: Ed. FIOCRUZ; 2014.

WEISS, C. H. Evaluation: methods for studing programs and policies. 2. ed. UpperSaddle River, NJ: Prentice Hall, 1998.

WHOLEY, J. S. Evaluability assessment. $2^{\text {nd }}$ ed. San Francisco: Jossey-Bass, 2004. 